\title{
GABAergic circuits underpin valuative processing
}

\author{
Dave J. Hayes* \\ Division of Brain, Imaging and Behaviour-Systems Neuroscience, Toronto Western Research Institute, Toronto Western \\ Hospital, University Health Network, Toronto, ON, Canada
}

Keywords: affect, appetitive, aversive, emotion, limbic, punishment, reward, valence

Affect is the fundamental neuropsychological state combining value- and arousal-related processes underpinning emotion and mood. A major goal of the emerging field of affective science is to explain the mechanisms of valuation within the brain. A core network of brain activity is seen across mammals in response to appetitive or aversive stimuli, and appears to be largely independent of stimulus modality (Bissonette et al., 2014; Hayes et al., 2014a). However, the underlying mechanisms of valuation (i.e., appetitive- and aversive-related brain activity) are unclear, and there is particularly little information about how these two valuative networks interact. One candidate which is likely central to the activity of both networks is the neurotransmitter $\gamma$-aminobutyric acid (GABA). Here, I briefly discuss some of the evidence pointing to GABA as a central player in mediating appetitive and aversive activity throughout the brain. The broader implication is that the role of GABA in valuative processing may be at the heart of affective regulation, and thus also important for a wide variety of psychological phenomena, from emotion (Stan et al., 2014) and impulsivity (Hayes et al., 2014b) to sense of self (Wiebking et al., 2014a,b).

OPEN ACCESS

Edited by: Mikhail Lebedev, Duke University, USA

Reviewed by:

Vinay V. Parikh,

Temple University, USA Jose Bargas,

Universidad Nacional Autónoma de

México, Mexico

Gregory B. Bissonette,

University of Maryland, USA

*Correspondence:

Dave J. Hayes, dave.hayes@utoronto.ca

Received: 11 March 2015 Accepted: 26 April 2015 Published: 12 May 2015

Citation:

Hayes DJ (2015) GABAergic circuits underpin valuative processing.

Front. Syst. Neurosci. 9:76. doi: 10.3389/fnsys.2015.00076

\section{Keys to Understanding GABA Circuitry}

An exploration of GABA in appetitive and aversive behavior began following its identification in the mammalian brain (Roberts and Frankel, 1950). Although central dopamine was discovered seven years later, many barriers to GABA-related research-including its relative ubiquity throughout the brain, the robust effects of GABAergic drugs administered systemically (e.g., which can easily lead to seizures or immobility), and little knowledge about GABAergic neurocircuitry-has led to a much greater understanding of dopamine in this context (Iversen and Iversen, 2007). Early advances in rodents were nonetheless made delineating key roles for GABA in consummatory behavior, stress, and anxiety (Kelly et al., 1977; Biggio et al., 1990). Studies such as these revealed that beyond dopamine, GABA was involved in mediating motivated behaviors in widespread, but regionally-selective ways (Kelly et al., 1977), and that dynamic cortical and subcortical changes to GABAergic microcircuits were involved (Biggio et al., 1990).

Improved mapping of the extensive brain GABAergic circuits (illustrated in Figure 1), coupled with technological advances in detection and manipulation, have partly driven the recent focus of the role of GABA, and its sister excitatory neurotransmitter glutamate, in value-related processing. Moreover, structural advances have continued steadily, from the identification of key GABAergic hubs, such as the basal ganglia and nucleus accumbens (Groenewegen and Russchen, 1984), to more

Abbreviations: Ctx, cortex; DA, dopamine; Amyg, amygdala; GABA, gamma-aminobutyric acid; GP, globus pallidus; LHb, Lateral habenula; Motor ctx, motor cortices including premotor, supplementary motor, and frontal eye fields; NAcbC, nucleus accumbens septi core; NAcbS, nucleus accumbens septi shell; PFC, prefrontal cortex; SN substantia nigra; Thal, thalamus; VP, ventral pallidum; VTA, ventral tegmental area. 


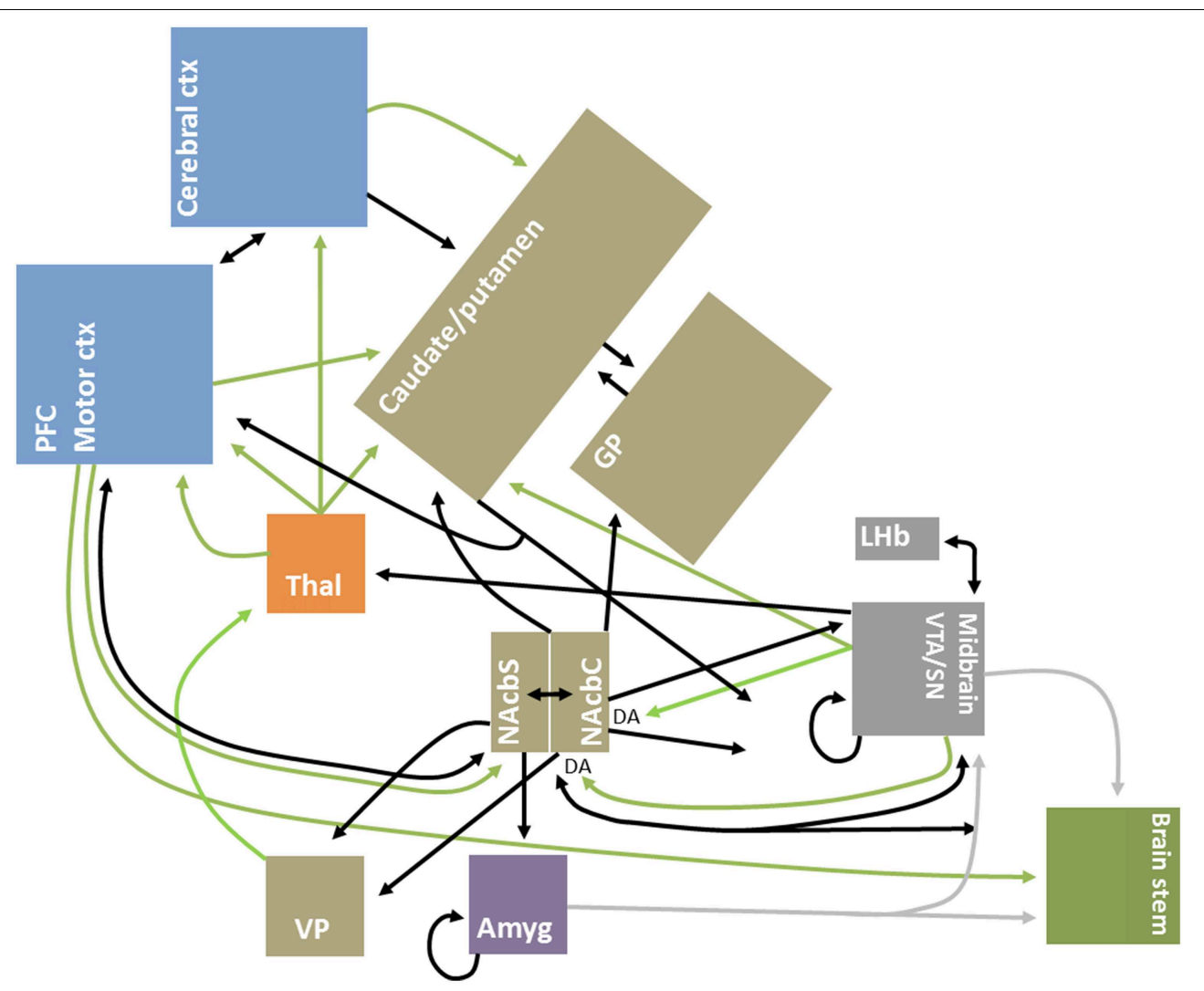

FIGURE 1 | Simplified schematic diagram of GABAergic circuitry underlying valuative processing. Inhibitory connections, mainly GABAergic, are indicated by black arrows; excitatory connections, which are glutamatergic unless otherwise indicated, are indicated by green arrows.
Brain regions are grouped by neocortex (blue), basal ganglia (brown), thalamus (orange), midbrain/mesencephalon (gray), amygdala (purple) and brainstem (green) for illustrative purposes. Adapted from Dalley et al. (2011), Squire et al. (2012), and Nieh et al. (2013). recent elaborations on the nature of inter- and intra-regional short and long-range GABAergic connections (Caputi et al., 2013). GABA circuits are uniquely situated as both local communicators and whole-brain integrators, given their dynamic control over excitatory and inhibitory signal conduction through axo-dendritic and astrocytic synapses (Frola et al., 2013) and their role in broader oscillatory and synchronistic activities (Melzer et al., 2012).

GABAergic interneurons, particularly parvalbumincontaining, are fundamental drivers of cortical oscillations, which emerging research suggests may be a fundamental context-dependent mechanism for intra- and inter-regional communication (Sohal, 2012; Jadi and Sejnowski, 2015). For instance, beyond the hippocampus and select regions of the neocortex, where these oscillations are better studied, there is also evidence for GABA-driven oscillatory synchronization within the striatum (Sharott et al., 2009) - a hub region connecting the cortex to the basal ganglia and heavily involved in motivation and valuative processing. Moreover, there is evidence that GABA cells are necessary for sustained reward-related signaling, as noted in a study of reversal learning in mice with decreased levels of prefrontal cortical GABAergic interneurons (Bissonette et al., 2015). Going forward, I briefly discuss a sample of recent studies which support the fundamental role of GABA in valuative processing and highlight future directions which will likely contribute to advances in this area.

\section{GABAergic Microcircuits Regulate Valuative Networks}

The present focus on GABA is not intended to ignore the important role played by other neurotransmitters. GABAglutamatergic dynamics are fundamentally important for a complete understanding of circuit dynamics, as has been underscored by findings of neuronal co-release in value-related regions (Root et al., 2014) and multimodal neuroimaging studies in humans (Duncan et al., 2014). Nonetheless, GABA likely plays a unique role in neural control as, for instance, local and long-range GABAergic projections are highly diffuse and GABAergic synapses can precisely target the dendritic shafts of pyramidal cells, allowing for earlier neuronal signal gating in comparison to glutamatergic synapses (Chiu et al., 2013). Moreover, some GABAergic projections are noted to bypass the typical brainstem-thalamo-cortical and cortico-basal ganglia-thalamo-cortical connections, including for instance the direct meso-cortico, meso-limbic and pallidal-cortical pathways (Cohen et al., 2012; Nieh et al., 
2013; Saunders et al., 2015)—see Figure 1 for illustrative purposes.

Studies investigating neurotransmitter involvement in combined appetitive and aversive processing are limited in general and sparser for GABA (Hayes et al., 2014a). Existing studies in rodents using combined electrophysiological and optogenetic techniques have shown that the majority of ventral tegmental area (VTA) cells respond to value-related stimuli. This is interesting as one-third to half of VTA cells are GABAergic (Swanson, 1982) and may also include cells which co-release dopamine and GABA (Tritsch et al., 2012). While dopaminergic cells typically increase activity to appetitive stimuli as might be expected, some GABAergic cells can increase activity in response to aversive stimuli, be modulated by reward cues (Cohen et al., 2012), and also appear to help signal expected rewards (Lammel et al., 2012). Many of these cells are flexibly responsive to both appetitive and aversive cues, suggesting that they respond to the learned value of the stimulus and not its static properties (Kim et al., 2010). Networks of intra-VTA GABAergic cells, however, show increased correlations to theta band power in response to appetitive, but not aversive, cues (Kim et al., 2012) and so might be involved in the integration of appetitive networks needed to learn about, and maintain, reward-related behaviors such as electrical brain self-stimulation (Steffensen et al., 2001; Lassen et al., 2007).

Though the nucleus accumbens is comprised almost entirely of short- and long-range GABAergic projections and is a high-density region tasked with integrating motor, sensory, and valuative/motivational signals (Mogenson et al., 1980), it has been underexplored in this context (Carlezon and Thomas, 2009; Hayes et al., 2014a,b). Feeding studies have shown that presumably inhibiting the GABAergic cells of the accumbens shell corresponds to increases in appetitive feeding behaviors (Stratford and Kelley, 1997). Others have identified a rostrocaudal gradient in the shell, whereby $\mathrm{GABA}_{\mathrm{A}}$ receptor activation in the rostral shell leads to increases in appetitive feeding, conditioned place preference and sucrose responding, and caudal activation results in aversive, defensive, behaviors (Reynolds and Berridge, 2002). Although our group found similar orexigenic effects of GABAergic drugs in the rostral shell, we noted a clear increase and decrease in electrical brain self-stimulation following intra-accumbens $\mathrm{GABA}_{\mathrm{A}}$ receptor blockade and stimulation, respectively, at the same injection sites (Hayes et al., 2011). These seemingly opposing results suggest that although GABAergic accumbens microcircuits are fundamental to valuative processing, subtle differences in their activation are likely involved in differentiating responses to different kinds of appetitive and aversive stimuli. One clear possibility is that valuative GABAergic signaling is contextdependent on the temporal interplay with other biochemicals, such as glutamate (Clements and Greenshaw, 2005; Richard and Berridge, 2011).

The evidence for GABA as a central regulator in valuative processing is not simply limited to the VTA or accumbens. For instance, the GABAergic lateral habenula inhibits VTA-related medial prefrontal cortex dopaminergic projections and local GABAergic cells which are both tied to aversive processing and behavioral output (Lammel et al., 2012; Shabel et al., 2012). The activation of nucleus accumbens GABAergic cells are also known to inhibit ventral pallidal activity (Wang et al., 2014), which is an area that contributes to changes in valuative responding (Tindell et al., 2004). For example, inactivation of pallidum by stimulating inhibitory $\mathrm{GABA}_{\mathrm{A}}$ receptors results in the elimination of rewardrelated saccade responding in rhesus monkeys (Tachibana and Okihide, 2013). Interestingly, a recent study suggested that increases in feeding following intra-pallidal, but not intraaccumbens, $\mathrm{GABA}_{\mathrm{A}}$ receptor antagonism corresponded to a specific "fat craving" signal instead of general increases in appetitive activity (Covelo et al., 2014). Aversion-related activity may also involve GABAergic inhibition of infralimbic cortex in rats, a homolog to the primate medial prefrontal cortex, as has been demonstrated by showing that pain-related GABAergic inhibitions in the prefrontal cortex are reversed following the local injection of $\mathrm{GABA}_{\mathrm{A}}$ receptor antagonists (Ji and Neugebauer, 2011) - though infralimbic activation in the absence of pain may also be anxiogenic (Bi et al., 2013). Moreover, $\mathrm{GABA}_{\mathrm{A}}$ receptor activation in the infralimbic cortex increases impulsive responding (Murphy et al., 2012), while activation in the prelimbic cortex reduces aversive behaviors such as fearpotentiated startle and freezing (Almada et al., 2015).

Beyond the regions of the extended amygdala noted above (e.g., nucleus accumbens shell, habenula), the amygdala itself is one region that deserves a brief note. Although its role in processing aversive stimuli is well-established, our understanding of its role in appetitive encoding is relatively recent -it is also considered mainly as a singular structure in human studies, though it is known to be made up of a number of uniquelyconnected nuclei (e.g., central, basolateral, and lateral) comprised of differing cell types (Phelps and LeDoux, 2005; Janak and Tye, 2015). Few studies have looked at how this region processes both appetitive and aversive stimuli and none have focused on GABAergic cells. Studies in primates and rodents using single cell basolateral and central area recordings showed that at least half of the cells sampled were value-responsive, sensory modalityindependent, consisted of general responders and those with preferences for either appetitive or aversive stimuli, and that there was no clear anatomical distribution for such cells across each subregion (Paton et al., 2006; Belova et al., 2007, 2008; Shabel and Janak, 2009). At least one study has also shown the importance of safety signaling for cells throughout the basal amygdala, identifying subpopulations of cells that respond to combinations of value and safety cues (Sangha et al., 2013). Of further interest, recent reports have described long-range GABAergic hippocampal- and intra-amygdalar projections likely involved in valuative processing (Bienvenu et al., 2015; McDonald and Zaric, 2015).

Taken together, and as underscored by Figure 1, these studies support the hypothesis that interconnected GABAergic microcircuits are a binding feature of valuative processing. Indeed, these circuits may be at the heart of whole-brain reinforcement or valuative networks (English et al., 2011; Vickery et al., 2011). Moreover, they likely also contribute to the intraregional integration and differentiation of appetitive and aversive signals (Hayes et al., 2014a). 


\section{Future Considerations}

A corollary of the hypothesis above is the emphasis on undiscovered intra- and inter-regional value-related GABAergic signaling throughout the brain. In this vein, our group showed in a human multimodal neuroimaging study that $\mathrm{GABA}_{\mathrm{A}}$ receptors in medial prefrontal cortex are negatively correlated to aversive signals in both the medial prefrontal region itself as well as distant sensorimotor clusters, but that $\mathrm{GABA}_{\mathrm{A}}$ receptors within different clusters of sensorimotor cortex respond differentially to the context of aversive stimuli (Hayes et al., 2013). Moreover, we reviewed the human and rodent literature on impulsivity and GABA, and concluded that GABAergic networks throughout at least cortico-basal ganglia regions acted as a common substrate of impulsive behaviors (Hayes et al., 2014b).

We believe that affective/valuative networks are at the core of many psychological phenomena, from emotion (Stan et al., 2014) and impulsivity to sense of self (Wiebking et al., 2014a,b), and may even be fundamental to the initial recruitment of cognitive control (Inzlicht et al., 2015). Indeed, some neuroimaging studies have identified a common wide-spread network of regions which may be common to these processes (Northoff and Hayes, 2011; Amft et al., 2015). Future studies using complex multimodal neuroimaging approaches will be necessary to elaborate and connect the present neural and biochemical findings in humans (Duncan et al., 2014). These should also include in vivo neuroanatomical explorations of affective circuitry white matter, by for instance using recent advancements in multitensor tractography (Chen et al., 2014).

Conceptually, it is important to note that when discussing a "system" of any sort in neuroscience (e.g., GABAergic, valuative) one is often taking a broad sum-of-parts operational definition. Because the entirety, and mechanistic underpinnings, of such systems are incomplete, and cannot be fully understood in isolation, these terms become placeholders for our dynamic knowledge (see LeDoux, 2012; Gross and Barrett, 2013; Hayes et al., 2014a for related discussions). For example, future research will have to continue to identify clusters of GABAergic cells which make up value-processing microcircuits as well as their connections to other value- and non-value related clusters, including other cell types, such that a better understanding of their true function becomes clearer (and probably resulting in clearer delineations between multiple "systems"). Analogous advances in network neuroscience have been made to identify

\section{References}

Almada, R. C., Coimbra, N. C., and Brandão, M. L. (2015). Medial prefrontal cortex serotonergic and GABAergic mechanisms modulate the expression of contextual fear: intratelencephalic pathways and differential involvement of cortical subregions. Neuroscience 284, 988-997. doi: 10.1016/j.neuroscience.2014.11.001

Amft, M., Bzdok, D., Laird, A. R., Fox, P. T., Schilbach, L., and Eickhoff, S. B. (2015). Definition and characterization of an extended social-affective default network. Brain Struct. Funct. 220, 1031-1049. doi: 10.1007/s00429-0130698-0 many major nodes/hubs (i.e., clusters), edges (i.e., connections), and the interactions within and between such brain networks (Behrens and Sporns, 2012) - while most of this work is being done in humans, progress on the vast animal literature has also been made (Ikemoto, 2010). At this point, the greatest advances at the molecular-cellular level of understanding are likely being made through the identification and spatiotemporal electrochemical characterization of value-related microcircuits, for instance in the traditional mesocorticolimbic circuit (e.g., Nieh et al., 2013; Lammel et al., 2014). Indeed, the bulk of information connecting behavior to underlying mechanisms is confined to this value-related circuit, with disparate results for other areas. Moreover, behavioral-cellular/neurochemical connections related to GABA have been mainly restricted to single regions, such as the VTA, nucleus accumbens, and areas of the prefrontal cortex, although recent experiments have focused increasingly on inter-regional interactions (Lammel et al., 2012; Shabel et al., 2012; Hayes et al., 2013; Wang et al., 2014).

Going forward, future studies will also need to clearly answer the question of how brain areas within similar affective networks parse aversion- and appetitive-related neural signals, while also providing mechanisms for fast intraregional communication. Recent reviews of the human and animal literature have provided some insight to this question (Bissonette et al., 2014; Hayes et al., 2014a; Lindquist et al., 2015), but more work is needed. For instance, the significance, if any, of structures which show asymmetrical activity is unclear, e.g., appetitive and aversive stimuli may result in more dopamine in the right and left accumbens, respectively (Besson and Louilot, 1995). Moreover, how these neural processes are translated at the behavioral or "cognitive" level is of equal importance. Can appetitive and aversive stimuli be subjectively, consciously, experienced simultaneously (Barrett et al., 2007)? Why do some people experience painful experiences as pleasurable, and is there any connection to those who prefer to self-administer aversive stimuli rather than be alone with their own thoughts (Wilson et al., 2014)?

\section{Acknowledgments}

This work was partially supported by a Canadian Institutes of Health Research Postdoctoral Fellowship. Thanks to Dr Jeffrey Dalley for related discussions. 10.1146/annurev.psych.58.110405.085709

Behrens, T. E. J., and Sporns, O. (2012). Human connectomics. Curr. Opin. Neurobiol. 22, 144-153. doi: 10.1016/j.conb.2011.08.005

Belova, M. A., Paton, J. J., Morrison, S. E., and Salzman, C. D. (2007). Expectation modulates neural responses to pleasant and aversive stimuli in primate amygdala. Neuron 55, 970-984. doi: 10.1016/j.neuron.2007.08.004

Belova, M. A., Paton, J. J., and Salzman, C. D. (2008). Moment-to-moment tracking of state value in the amygdala. J. Neurosci. 28, 10023-10030. doi: 10.1523/JNEUROSCI.1400-08.2008 
Besson, C., and Louilot, A. (1995). Asymmetrical involvement of mesolimbic dopaminergic neurons in affective perception. Neuroscience 68, 963-968. doi: 10.1016/0306-4522(95)00255-H

Bi, L. L., Wang, J., Luo, Z. Y., Chen, S. P., Geng, F., Chen, Y. H., et al. (2013). Enhanced excitability in the infralimbic cortex produces anxiety-like behaviors. Neuropharmacology 72, 148-156. doi: 10.1016/j.neuropharm.2013.04.048

Bienvenu, T. C. M., Busti, D., Micklem, B. R., Mansouri, M., Magill, P. J., Ferraguti, F., et al. (2015). Large intercalated neurons of amygdala relay noxious sensory information. J. Neurosci. 35, 2044-2057. doi: 10.1523/JNEUROSCI.132314.2015

Biggio, G., Concas, A., Corda, M. G., Giorgi, O., Sanna, E., and Serra, M. (1990). GABAergic and dopaminergic transmission in the rat cerebral cortex: effect of stress, anxiolytic and anxiogenic drugs. Pharmacol. Ther. 48, 121-142. doi: 10.1016/0163-7258(90)90077-F

Bissonette, G. B., Gentry, R. N., Padmala, S., Pessoa, L., and Roesch, M. R. (2014). Impact of appetitive and aversive outcomes on brain responses: linking the animal and human literatures. Front. Syst. Neurosci. 8:24. doi: 10.3389 /fnsys. 2014.00024

Bissonette, G. B., Schoenbaum, G., Roesch, M. R., and Powell, E. M. (2015). Interneurons are necessary for coordinated activity during reversal learning in orbitofrontal cortex. Biol. Psychiatry, 77, 454-464. doi: 10.1016/j.biopsych.2014.07.023

Caputi, A., Melzer, S., Michael, M., and Monyer, H. (2013). The long and short of GABAergic neurons. Curr. Opin. Neurobiol. 23, 179-186. doi: 10.1016/j.conb.2013.01.021

Carlezon, W. A., and Thomas, M. J. (2009). Biological substrates of reward and aversion: a nucleus accumbens activity hypothesis. Neuropharmacology 56, 122-132. doi: 10.1016/j.neuropharm.2008.06.075

Chen, D., Strauss, I., Hayes, D., Davis, K., and Hodaie, M. (2014). Age-related changes in diffusion tensor imaging metrics of fornix subregions in healthy humans. Stereotact. Funct. Neurosurg. 93, 151-159. doi: 10.1159/000368442

Chiu, C. Q., Lur, G., Morse, T. M., Carnevale, N. T., Ellis-Davies, G. C. R., and Higley, M. J. (2013). Compartmentalization of GABAergic inhibition by dendritic spines. Science 340, 759-762. doi: 10.1126/science.1234274

Clements, R. L. H., and Greenshaw, A. J. (2005). Facilitation of brain stimulation reward by MK-801 (dizocilpine) may be independent of D2-like dopamine receptor stimulation in rats. Psychopharmacology (Berl). 182, 65-74. doi: 10.1007/s00213-005-0039-y

Cohen, J. Y., Haesler, S., Vong, L., Lowell, B. B., and Uchida, N. (2012). Neurontype-specific signals for reward and punishment in the ventral tegmental area. Nature 482, 85-88. doi: 10.1038/nature10754

Covelo, I. R., Patel, Z. I., Luviano, J. A., Stratford, T. R., and Wirtshafter, D. (2014). Manipulation of GABA in the ventral pallidum, but not the nucleus accumbens, induces intense, preferential, fat consumption in rats. Behav. Brain Res. 270, 316-325. doi: 10.1016/j.bbr.2014.05.032

Dalley, J. W., Everitt, B. J., and Robbins, T. W. (2011). Impulsivity, compulsivity, and top-down cognitive control. Neuron 69, 680-694. doi: 10.1016/j.neuron.2011.01.020

Duncan, N. W., Wiebking, C., and Northoff, G. (2014). Associations of regional GABA and glutamate with intrinsic and extrinsic neural activity in humansa review of multimodal imaging studies. Neurosci. Biobehav. Rev. 47C, 36-52. doi: 10.1016/j.neubiorev.2014.07.016

English, D. F., Ibanez-Sandoval, O., Stark, E., Tecuapetla, F., Buzsáki, G., Deisseroth, K., et al. (2011). GABAergic circuits mediate the reinforcementrelated signals of striatal cholinergic interneurons. Nat. Neurosci. 15, 123-130. doi: $10.1038 / \mathrm{nn} .2984$

Frola, E., Patrizi, A., Goetz, T., Medrihan, L., Petrini, E. M., Barberis, A., et al. (2013). Synaptic competition sculpts the development of GABAergic axo-dendritic but not perisomatic synapses. PLOS ONE 8:e56311. doi: 10.1371/journal.pone.0056311

Groenewegen, H., and Russchen, F. (1984). Organization of the efferent projections of the nucleus accumbens to pallidal, hypothalamic, and mesencephalic structures: a tracing and immunohistochemical study in the cat. J. Comput. Neurol. 223, 347-367. doi: 10.1002/cne.902230303

Gross, J. J., and Barrett, L. F. (2013). The emerging field of affective science. Emotion 13, 997-998. doi: 10.1037/a0034512

Hayes, D. J., Duncan, N. W., Wiebking, C., Pietruska, K., Qin, P., Lang, S., et al. (2013). GABAA receptors predict aversion-related brain responses: an
fMRI-PET investigation in healthy humans. Neuropsychopharmacology 38, 1438-1450. doi: 10.1038/npp.2013.40

Hayes, D. J., Duncan, N. W., Xu, J., and Northoff, G. (2014a). A comparison of neural responses to appetitive and aversive stimuli in humans and other mammals. Neurosci. Biobehav. Rev. 45, 350-368. doi: 10.1016/j.neubiorev.2014.06.018

Hayes, D. J., Hoang, J., and Greenshaw, A. J. (2011). The role of nucleus accumbens shell GABA receptors on ventral tegmental area intracranial self-stimulation and a potential role for the 5-HT(2C) receptor. J. Psychopharmacol. 25, 1661-1675. doi: 10.1177/0269881110389212

Hayes, D. J., Jupp, B., Sawiak, S. J., Merlo, E., Caprioli, D., and Dalley, J. W. (2014b). Brain $\gamma$-aminobutyric acid: a neglected role in impulsivity. Eur. J. Neurosci. 39, 1921-1932. doi: 10.1111/ejn.12485

Ikemoto, S. (2010). Brain reward circuitry beyond the mesolimbic dopamine system: a neurobiological theory. Neurosci. Biobehav. Rev. 35, 129-150. doi: 10.1016/j.neubiorev.2010.02.001

Inzlicht, M., Bartholow, B. D., and Hirsh, J. B. (2015). Emotional foundations of cognitive control. Trends Cogn. Sci. 19, 1-7. doi: 10.1016/j.tics.2015. 01.004

Iversen, S. D., and Iversen, L. L. (2007). Dopamine: 50 years in perspective. Trends Neurosci. 30, 188-193. doi: 10.1016/j.tins.2007.03.002

Jadi, M. P., and Sejnowski, T. J. (2015). Cortical oscillations arise from contextual interactions that regulate sparse coding. Proc. Natl. Acad. Sci.U.S.A. 112, E341-E341. doi: 10.1073/pnas.1405300111

Janak, P. H., and Tye, K. M. (2015). From circuits to behaviour in the amygdala. Nature 517, 284-292. doi: 10.1038/nature14188

Ji, G., and Neugebauer, V. (2011). Pain-related deactivation of medial prefrontal cortical neurons involves mGluR1 and GABAA receptors. J. Neurophysiol. 106, 2642-2652. doi: 10.1152/jn.00461.2011

McDonald, A. J., and Zaric, V. (2015). GABAergic somatostatin-immunoreactive neurons in the amygdala project to the entorhinal cortex. Neuroscience 290, 227-242. doi: 10.1016/j.neuroscience.2015.01.028

Kelly, J., Alheid, G. F., Newberg, A., and Grossman, S. P. (1977). GABA stimulation and blockade in the hypothalamus and midbrain: effects on feeding and locomotor activity. Pharmacol. Biochem. Behav. 7, 537-541. doi: 10.1016/00913057(77)90250-7

Kim, Y. B., Matthews, M., and Moghaddam, B. (2010). Putative gammaaminobutyric acid neurons in the ventral tegmental area have a similar pattern of plasticity as dopamine neurons during appetitive and aversive learning. Eur. J. Neurosci. 32, 1564-1572. doi: 10.1111/j.1460-9568.2010. 07371.x

Kim, Y., Wood, J., and Moghaddam, B. (2012). Coordinated activity of ventral tegmental neurons adapts to appetitive and aversive learning. PLoS ONE 7:e29766. doi: 10.1371/journal.pone.0029766

Lammel, S., Lim, B. K., and Malenka, R. C. (2014). Reward and aversion in heterogeneous midbrain dopamine system. Neuropharmacology 76, 351-359. doi: 10.1016/j.neuropharm.2013.03.019

Lammel, S., Lim, B. K., Ran, C., Huang, K. W., Betley, M. J., Tye, K. M., et al. (2012). Input-specific control of reward and aversion in the ventral tegmental area. Nature 491, 212-217. doi: 10.1038/nature11527

Lassen, M. B., Brown, J. E., Stobbs, S. H., Gunderson, S. H., Maes, L., Valenzuela, C. F., et al. (2007). Brain stimulation reward is integrated by a network of electrically coupled GABA neurons. Brain Res. 1156, 46-58. doi: 10.1016/j.brainres.2007.04.053

LeDoux, J. (2012). Rethinking the emotional brain. Neuron 73, 653-676. doi: 10.1016/j.neuron.2012.02.004

Lindquist, K. A., Satpute, A. B., Wager, T. D., Weber, J., and Barrett, L. F. (2015). The brain basis of positive and negative affect: evidence from a meta-analysis of the human neuroimaging literature. Cereb. Cortex doi: 10.1093/cercor/bhv001. [Epub ahead of print].

Melzer, S., Michael, M., Caputi, A., Eliava, M., Fuchs, E. C., Whittington, M., et al. (2012). Long-range-projecting GABAergic neurons modulate inhibition in hippocampus and entorhinal cortex. Science 335, 1506-1510. doi: $10.1126 /$ science. 1217139

Mogenson, G. J., Jones, D. L., and Yim, C. Y. (1980). From motivation to action: functional interface between the limbic system and the motor system. Prog. Neurobiol. 14, 69-97. doi: 10.1016/0301-0082(80) 90018-0 
Murphy, E. R., Fernando, A. B. P., Urcelay, G. P., Robinson, E. S. J., Mar, A. C., Theobald, D. E. H., et al. (2012). Impulsive behaviour induced by both NMDA receptor antagonism and GABAA receptor activation in rat ventromedial prefrontal cortex. Psychopharmacology (Berl). 219, 401-410. doi: 10.1007/s00213-011-2572-1

Nieh, E. H., Kim, S.-Y., Namburi, P., and Tye, K. M. (2013). Optogenetic dissection of neural circuits underlying emotional valence and motivated behaviors. Brain Res. 1511, 73-92. doi: 10.1016/j.brainres.2012.11.001

Northoff, G., and Hayes, D. J. (2011). Is our self nothing but reward? Biol. Psychiatry 69, 1019-1025. doi: 10.1016/j.biopsych.2010.12.014

Paton, J. J., Belova, M. A., Morrison, S. E., and Salzman, C. D. (2006). The primate amygdala represents the positive and negative value of visual stimuli during learning. Nature 439, 865-870. doi: 10.1038/nature04490

Phelps, E. A., and LeDoux, J. E. (2005). Contributions of the amygdala to emotion processing: from animal models to human behavior. Neuron $48,175-187$. doi: 10.1016/j.neuron.2005.09.025

Reynolds, S. M., and Berridge, K. C. (2002). Positive and negative motivation in nucleus accumbens shell: bivalent rostrocaudal gradients for GABA-elicited eating, taste "liking"/“disliking" reactions, place preference/avoidance, and fear. J. Neurosci. 22, 7308-7320.

Richard, J. M., and Berridge, K. C. (2011). Metabotropic glutamate receptor blockade in nucleus accumbens shell shifts affective valence towards fear and disgust. Eur. J. Neurosci. 33, 736-747. doi: 10.1111/j.1460-9568.2010. 07553.x

Roberts, E., and Frankel, S. (1950). $\gamma$-Aminobutyric acid in brain: its formation from glutamic acid. J. Biol. Chem. 187, 55-63.

Root, D. H., Mejias-Aponte, C. A., Zhang, S., Wang, H. L., Hoffman, A. F., Lupica, C. R., et al. (2014). Single rodent mesohabenular axons release glutamate and GABA. Nat. Neurosci. 17, 1543-1551. doi: 10.1038/nn.3823 Root, D.H., Mejias-Aponte, C.A., Zhang, S., Wang, H.L., Hoffman, A.F., Lupica, C.R., Morales, $\mathrm{M}$.

Sangha, S., Chadick, J. Z., and Janak, P. H. (2013). Safety encoding in the basal amygdala. J. Neurosci. 33, 3744-3751. doi: 10.1523/JNEUROSCI.330212.2013

Saunders, A., Oldenburg, I. A., Berezovskii, V. K., Johnson, C. A., Kingery, N. D., Elliott, H. L., et al. (2015). A direct GABAergic output from the basal ganglia to frontal cortex. Nature doi: 10.1038/nature14179. [Epub ahead of print].

Shabel, S. J., and Janak, P. H. (2009). Substantial similarity in amygdala neuronal activity during conditioned appetitive and aversive emotional arousal. Proc. Natl. Acad. Sci. U.S.A. 106, 15031-15036. doi: 10.1073/pnas.0905580106

Shabel, S. J., Proulx, C. D., Trias, A., Murphy, R. T., and Malinow, R. (2012). Input to the lateral habenula from the basal ganglia is excitatory, aversive, and suppressed by serotonin. Neuron 74, 475-481. doi: 10.1016/j.neuron.2012.02.037

Sharott, A., Moll, C. K. E., Engler, G., Denker, M., Grün, S., and Engel, A. K. (2009). Different subtypes of striatal neurons are selectively modulated by cortical oscillations. J. Neurosci. 29, 4571-4585. doi: 10.1523/JNEUROSCI.509708.2009

Sohal, V. S. (2012). Insights into cortical oscillations arising from optogenetic studies. Biol. Psychiatry 71, 1039-1045. doi: 10.1016/j.biopsych.2012.01.024

Squire, L., Berg D., Bloom, F., du Lac, S., Ghosh, A., and Spitzer, N. (eds.). (2012). Fundamental Neuroscience, 4th Edn. USA: Academic Press.
Stan, A. D., Schirda, C. V., Bertocci, M. A., Bebko, G. M., Kronhaus, D. M., Aslam, H. A., et al. (2014). Glutamate and GABA contributions to medial prefrontal cortical activity to emotion: implications for mood disorders. Psychiatry Res. 223, 253-260. doi: 10.1016/j.pscychresns.2014.05.016

Steffensen, S. C., Lee, R. S., Stobbs, S. H., and Henriksen, S. J. (2001). Responses of ventral tegmental area GABA neurons to brain stimulation reward. Brain Res. 906, 190-197. doi: 10.1016/S0006-8993(01)02581-1

Stratford, T. R., and Kelley, A. E. (1997). GABA in the nucleus accumbens shell participates in the central regulation of feeding behavior. J. Neurosci. 17, $4434-4440$.

Swanson, L. W. (1982). The projections of the ventral tegmental area and adjacent regions: a combined fluorescent retrograde tracer and immunofluorescence study in the rat. Brain Res. Bull. 9, 321-353. doi: 10.1016/0361-9230(82)90145-9

Tachibana, Y., and Okihide, H. (2013). The primate ventral pallidum encodes expected reward value and regulates motor action. Neuron 62, 985-994. doi: 10.1016/j.neuron.2012.09.030

Tindell, A. J., Berridge, K. C., and Aldridge, J. W. (2004). Ventral pallidal representation of pavlovian cues and reward: population and rate codes. J. Neurosci. 24, 1058-1069. doi: 10.1523/JNEUROSCI.1437-03.2004

Tritsch, N. X., Ding, J. B., and Sabatini, B. L. (2012). Dopaminergic neurons inhibit striatal output through non-canonical release of GABA. Nature 490, 262-266. doi: 10.1038/nature11466

Vickery, T. J., Chun, M. M., and Lee, D. (2011). Ubiquity and specificity of reinforcement signals throughout the human brain. Neuron $72,166-177$. doi: 10.1016/j.neuron.2011.08.011

Wang, L., Shen, M., Yu, Y., Tao, Y., Zheng, P., Wang, F., et al. (2014). Optogenetic activation of GABAergic neurons in the nucleus accumbens decreases the activity of the ventral pallidum and the expression of cocainecontext-associated memory. Int. J. Neuropsychopharmacol. 17, 753-763. doi: $10.1017 /$ S1461145713001570

Wiebking, C., Duncan, N. W., Qin, P., Hayes, D. J., Lyttelton, O., Gravel, P., et al. (2014a). External awareness and GABA-A multimodal imaging study combining fMRI and [(18) F] flumazenil-PET. Hum. Brain Mapp. 35, 173-184. doi: 10.1002/hbm.22166

Wiebking, C., Duncan, N. W., Tiret, B., Hayes, D. J., Marja?ska, M., Doyon, J., et al. (2014b). GABA in the insula - a predictor of the neural response to interoceptive awareness. Neuroimage 86, 10-18. doi: 10.1016/j.neuroimage.2013.04.042

Wilson, T. D., Reinhard, D. A., Westgate, E. C., Gilbert, D. T., Ellerbeck, N., Hahn, C., et al. (2014). Just think: the challenges of the disengaged mind. Science 345, 75-77. doi: 10.1126/science. 1250830

Conflict of Interest Statement: The author declares that the research was conducted in the absence of any commercial or financial relationships that could be construed as a potential conflict of interest.

Copyright (c) 2015 Hayes. This is an open-access article distributed under the terms of the Creative Commons Attribution License (CC BY). The use, distribution or reproduction in other forums is permitted, provided the original author(s) or licensor are credited and that the original publication in this journal is cited, in accordance with accepted academic practice. No use, distribution or reproduction is permitted which does not comply with these terms. 